\title{
Template-free synthesis to micro-meso-macroporous hierarchy in nanostructured MIL-101(Cr) with enhanced catalytic activity
}

\author{
Tian Zhao ${ }^{1,5 \dagger}$, Songhe $\mathrm{Li}^{1 \dagger}$, Yu-Xuan Xiao ${ }^{1}$, Christoph Janiak ${ }^{4^{*}}$, Ganggang Chang ${ }^{1}$, Ge Tian ${ }^{1}$ and \\ Xiao-Yu Yang ${ }^{1,2,3^{*}}$
}

Hierarchical porous (HP) materials [1,2], having multimodal pore-size distribution, receive keen attention due to advantages offered by improved diffusion efficiency and mass transport. HP metal-organic frameworks (HPMOFs) is an emerging field focussing on delivering improved performance in catalysis [3,4], adsorption/ separation [5,6], sensorics [7] and energy storage [8,9], especially when bulky guest molecules are involved. Micropores usually offer high surface area while mesopores/ macropores will significantly enlarge the application as a host material to carry bulky anchoring molecular catalysts, large drug molecules and even nanomaterials. This is indeed an advantage for catalysis reaction or transformation without transportation limitations in a confined space. Some MOFs with the large pore-sizes of over $2 \mathrm{~nm}$ diameter are formally micro-/mesoporous in the defectfree crystalline state. Isoreticular expansion [10] allows synthesizing MOF materials with pore sizes of up to $10 \mathrm{~nm}$ [11]. Aside from those special cases of fragile and expensive MOFs, MOF materials of general importance could be synthesized in HP form using a templating method [12,13], post-synthetic modification/etching [1416], co-ligands/modulators [17] or kinetically controlled precipitation [18]. Most of the used methods are material specific, and the attainment of trimodal micro-/meso-/ macroporosity is still rarely reported.

MIL-101(Cr) $(\mathrm{MIL}=$ Materials Institute Lavoisier $)$ is one of the few MOFs having real prospects for practical applications [19]. It possesses spacious pores (maximum diameter is $\sim 34 \AA$, maximum entrance diameter is $\sim 15 \AA$ ) and high surface area (up to $\sim 4000 \mathrm{~m}^{2} \mathrm{~g}^{-1}$ ). Due to kinetic inertness of $\mathrm{Cr}(\mathrm{III})$, MIL-101(Cr) is one of the most chemically and hydrothermally stable MOFs, particularly promising for catalysis at elevated temperatures [20]. The targeted micro-/meso-/macroporous hierarchical porosity is scarcely reported for MIL-101(Cr). In general, MIL-101 $(\mathrm{Cr})$ is synthesized at relatively high temperature $\left(220^{\circ} \mathrm{C}\right)$ and sensitive to change of conditions. The efficient softtemplating strategy is hardly applicable at such temperatures, which demand special surfactants [21]. The universally applicable hard-templating is one possibility for creating hierarchical porosity, and it was demonstrated that organic polymers could form composites with MIL-101(Cr) [22,23]. Nevertheless, the straightforward and economical template-free approach is much more attractive.

The use of modulators, which are typically competing monodentate, terminal ligands, is a very general way of influencing the properties of MOF materials. Our screening of different modulators in the synthesis of MIL$101(\mathrm{Cr})$ indicated a formation of morphologically different products when acetic acid was used at comparably high concentration ( $>10 \mathrm{wt} \%$ aq. solution) [24]. Unlike in the case of mineral acids, hydrofluoric or benzoic acids

\footnotetext{
${ }^{1}$ State Key Laboratory of Advanced Technology for Materials Synthesis and Processing \& School of Materials Science and Engineering \& School of Chemistry, Chemical Engineering and Life Science, Wuhan University of Technology, Wuhan 430070, China

${ }^{2}$ Southern Marine Science and Engineering Guangdong Laboratory (Zhuhai) \& School of Chemical Engineering and Technology, Sun Yat-sen University, Zhuhai 519000, China

${ }^{3}$ School of Engineering and Applied Sciences, Harvard University, Cambridge, Massachusetts 02138, USA

${ }^{4}$ Institut für Anorganische Chemie und Strukturchemie, Universität Düsseldorf, Universitätsstr. 1, D-40225 Düsseldorf, Germany

${ }^{5}$ Key Laboratory of Advanced Packaging Materials and Technology of Hunan Province, School of Packaging and Materials Engineering, Hunan University of Technology, Zhuzhou 412007, China

† These authors contributed equally to this work.

* Corresponding authors (emails: janiak@uni-duesseldorf.de (Janiak C); xyyang@whut.edu.cn (Yang XY))
} 
and some other modulators yielding the product in a form of a usual light-green powder, the formation of a gel was observed. After thorough washing and drying, deepgreen glass-like sheets of the MOF were obtained, in which the crystallites of MIL-101(Cr) were tightly aggregated according to electron microscopic imaging. An optimized synthesis, performed with a molar ratio of $\mathrm{Cr}$ ion/acetic acid (1:12), yielded a distinct hierarchically micro-meso-macro-porous material (Fig. 1).

The hierarchical MIL structure is composed of columnar aggregates of nanocrystals, which are distinguishable on the majority of micrographs. The columns are mostly arranged in parallel and define indistinct tubular structures of secondary association (inset of Fig. 1a and Fig. S1). The diameters of the tubes vary
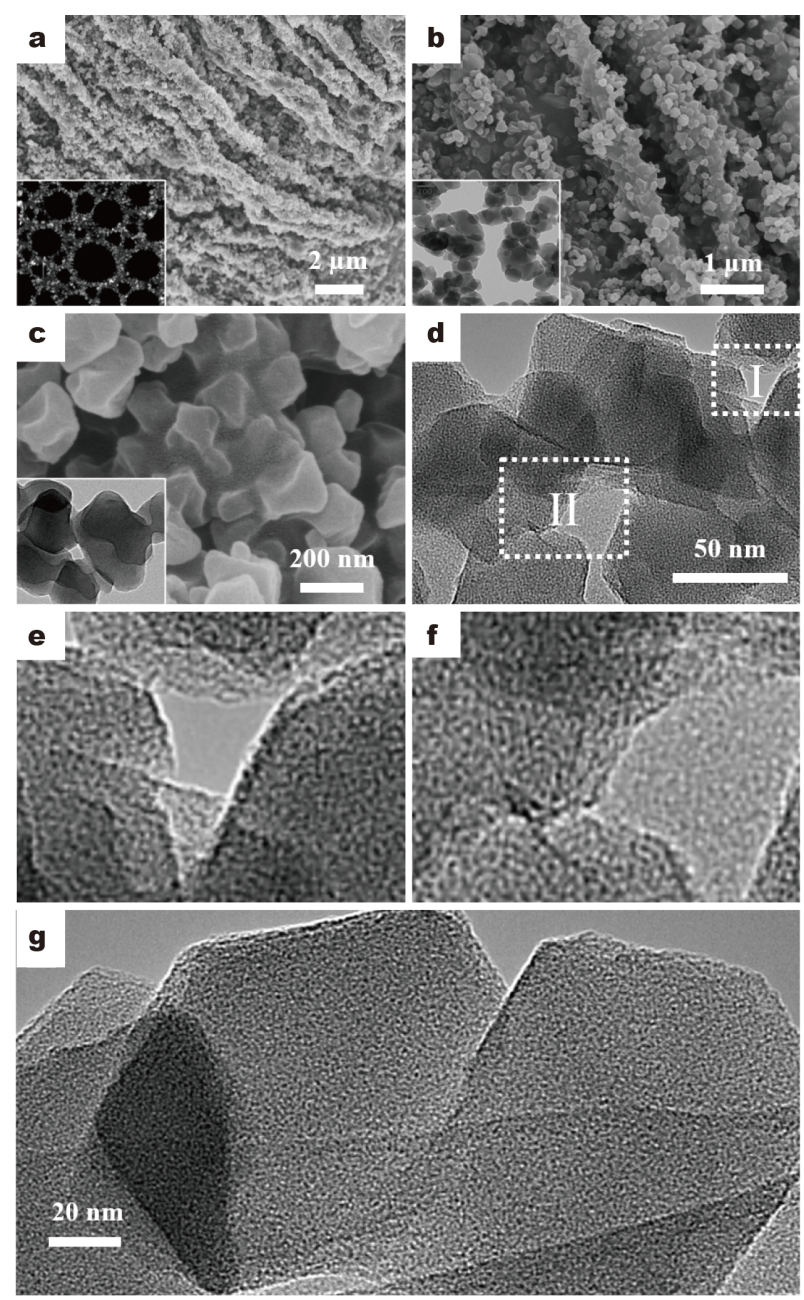

Figure $1(a-c)$ SEM and TEM (inset) images of (hierarchically porous) HP-MIL-101(Cr) under various magnifications. (d, g) HRTEM images of HP-MIL-101(Cr). (e, f) Magnified regions of I and II in (d), respectively. significantly around an approximate average in the range of $0.8-1 \mu \mathrm{m}$ (Fig. 1b). High-resolution scanning electron microscopy (SEM) and high-resolution transmission electron microscopy (HRTEM) images confirm the tight association, to the extent of intergrowth or fusion, of the constituting nanoparticles with an average size of $\sim 70 \mathrm{~nm}$ (Fig. 1c, d-g).

Powder X-ray diffraction (PXRD) measurements confirmed that hierarchically porous MIL-101(Cr) (named as HP-MIL-101(Cr)) is a pure, well-crystallized product. Both the small-angle and wide-angle regions of the pattern are practically indistinguishable from the pattern of the original MIL-101(Cr) (designated as O-MIL-101$(\mathrm{Cr})$ ), which was synthesized for direct comparison under similar conditions (with the same reaction temperature and time, but with $\mathrm{HNO}_{3}$ as additive) [24] (Fig. 2a). Also, both diffractograms of O- and HP-MIL-101(Cr) match the simulated pattern very well (Fig. S2).

Additionally, HP-MIL-101(Cr) showed a translucent

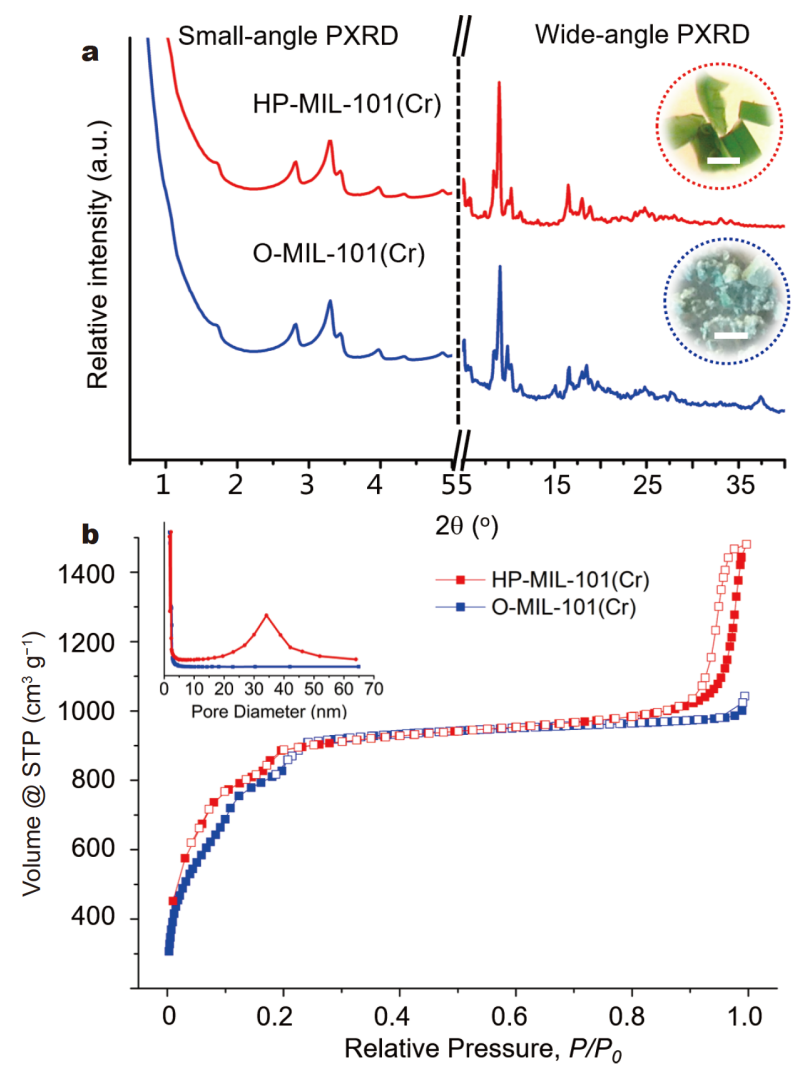

Figure 2 (a) Small-angle and wide-angle PXRD patterns of HP-MIL$101(\mathrm{Cr})$ and O-MIL-101(Cr); the photographs of the materials are given in the insets (for enlarged photos see Fig. S4). (b) Nitrogen sorption isotherms of HP-MIL-101(Cr) and MIL-101(Cr). The inset curves depict the BJH PSD (filled data points for adsorption, open data points for desorption). 
dark-green glassy-looking appearance, which was totally different from the opaque blue-green color of MIL-101 (Cr) (insets of Fig. 2a). With very similar structures on the scale below $10 \mathrm{~nm}$, the difference in light transmittance and color depth of the monolithic HP-MIL-101(Cr) materials is explained by an enhanced light-harvesting effect of macrochannels as light-transfer paths, which induce more photon flux onto the inner surface of HPMIL-101(Cr) and allow more light waves to penetrate deeper inside the monolithic HP- compared to O-MIL$101(\mathrm{Cr})$. A similar phenomenon was also found in macrochannel porous $\mathrm{TiO}_{2}$ [25].

Nitrogen sorption isotherms of O- and HP-MIL-101 $(\mathrm{Cr})$ are given in Fig. 2b. Both materials demonstrate Type I(b) sorption isotherms [26]. The second inflection point at relative pressure of $P / P_{0} \approx 0.2$ is present for Oand HP-MIL-101(Cr). This fine-structure is associated with the two pore-cage sizes and is present for highquality materials, e.g., synthesized with $\mathrm{HF}$ and $\mathrm{HNO}_{3}$ as modulators [19,24]. Furthermore, the Brunauer-EmmettTeller (BET) surface areas for O-MIL-101(Cr) and HPMIL-101(Cr) samples are quite close to 2903 and $2960 \mathrm{~m}^{2} \mathrm{~g}^{-1}$, respectively, which indicates that the two samples possess comparable porosity. Compared with the O-MIL-101(Cr) sample and typically reported MIL-101 (Cr) materials, the special feature of HP-MIL-101(Cr) is a distinctive Type IV end with a $\mathrm{H} 1$ hysteresis loop in the range of $0.9<P / P_{0}<0.99$, characteristic for a mesoporous material ( $>10 \mathrm{~nm}$ pore diameter) (Fig. 2b) [26]. The Barrett-Joyner-Halenda (BJH) analysis gives a broad pore size distribution (PSD) above $10 \mathrm{~nm}$, centered at $\sim 35 \mathrm{~nm}$ (Fig. 2b). Notably, the found range is close to the sizes of the observed nanoparticles, which define comparable sizes for the interparticle voids in the tight aggregate, as visible in the electronic microscopy images (Fig. 1c). Thus, the pore sizes of $\sim 1.5 \mathrm{~nm}$ (window of the MIL-101 $(\mathrm{Cr})), \sim 3 \mathrm{~nm}$ (cage pores in the MIL-101(Cr) crystal), $\sim 35 \mathrm{~nm}$ (as determined by $\mathrm{N}_{2}$ adsorption analysis) and $0.8-1 \mu \mathrm{m}$ witnessed by electronic microscopy cover a trimodal porous system with four main pore sizes involving micro-meso-macropores. Qualitative comparative tests of the adsorptive capabilities were performed by adsorption of the relatively large dye molecule Congo red from aqueous solution $(25 \times 10.5 \AA$ are the sizes of the Congo red molecule projection with minimal "width", relevant for crossing of the pore openings). Comparison of the optical densities of the dye solutions after adsorption by HP-MIL-101(Cr) and O-MIL-101(Cr) and removal of the solid phase indicated a much higher uptake by HP-MIL-101(Cr) (Fig. S3). We believe that this is at least partially kinetic in nature, as HP-MIL-101(Cr) with accessible small crystallites should demonstrate much higher mobility of the dye. Additionally, the smaller particle sizes decrease the adverse effect of poreclogging by the residual species in the MIL-101(Cr) pores; the effect should be very salient for large molecules.

As another alternative, phosphotungstic acid $\left(\mathrm{H}_{3} \mathrm{PW}_{12} \mathrm{O}_{40}\right.$, PTA, see Fig. $\mathrm{S} 5$ for the preparation details), which is an excellent acid catalyst, was attempted to load into HP-MIL-101(Cr) with the resulting compound named HP-MIL-101(Cr)@PTA. For comparison, O-MIL$101(\mathrm{Cr})$ was also used to prepare a PTA composite by the same method which was named O-MIL-101(Cr)@PTA. The element mapping of HP- and O-MIL-101(Cr)@PTA are shown in Figs S6, S7. The catalytic activities of HPMIL-101(Cr) and HP-MIL-101(Cr)@PTA were compared with their non-hierarchically porous analogues in a range of various oxidative and condensation reactions (Table 1).

In the indene (Runs 1,2) and 1-dodecene (Runs 3, 4) oxidation to the respective carboxylic acids by $\mathrm{H}_{2} \mathrm{O}_{2}$ in $\mathrm{CH}_{3} \mathrm{CN}$ [27], HP-MIL-101(Cr) is superior to O-MIL-101 (Cr) (Table 1, Figs S8, S9), particularly with regard to conversion (e.g., $92 \%$ vs. $78 \%$ for the conversion of 1 dodecene) (see the reaction schemes and detailed description).

HP-MIL-101(Cr)@PTA was also more active than OMIL-101(Cr)@PTA in the methanolysis of styrene oxide to 2-phenyl-2-methoxyethanol (Runs 5-8, Figs S10, S11) [17], in the bimolecular condensation/heterocyclization of benzaldehyde and 2-naphtol to the large dibenzoxantene molecule [20] (Runs 9-13) and in the trimolecular condensation of acetaldehyde, 2-napthol and acetamide to 1-(N-acetylaminophenylmethyl)-2-naphthol [20] (Runs 13-18) at elevated temperature of $130^{\circ} \mathrm{C}$ (Fig. S10, Table 1). In the methanolysis reaction of styrene oxide, the difference was particularly evident $(72 \%$ vs. $17 \%$ conversion, Table 1) and the recycled catalyst showed similar activity. In the synthesis of dibenzoxanthene, the turnover frequency (TOF) for HP-MIL-101(Cr)@PTA is larger than that for O-MIL-101(Cr)@PTA by a factor of 1.44 (18.9 vs. $\left.13.1 \mathrm{mmol} \mathrm{g}^{-1} \mathrm{~min}^{-1}\right)$. Similarly, in the synthesis of 1-( $N$-acetylaminophenylmethyl)-2-naphthol, the TOF value is larger for the HP form of the PTAloaded composite by a factor of $1.40 \quad(45.9 \mathrm{vs}$. $\left.32.8 \mathrm{mmol} \mathrm{g}^{-1} \mathrm{~min}^{-1}\right)$. In the syntheses of dibenzoxanthene and 1-( $N$-acetylaminophenylmethyl)-2-naphthol, the action of HP-MIL-101(Cr)@PTA was similar to that of homogenous PTA catalysis (conversion: $90 \%$ vs. $92 \%$; $91 \%$ vs. 94\%), while the TOF value was slightly higher for the heterogenous catalyst (Table 1). Hierarchical porosity 
Table 1 Summary on catalytic reactions

\begin{tabular}{|c|c|c|c|c|}
\hline Run & Sample $^{\mathrm{a}}$ & Reaction & TOF $\left(\mathrm{mmol} \mathrm{g}^{-1} \min ^{-1}\right)^{\mathrm{f}}$ & Conversion (\%) \\
\hline 1 & O-MIL-101(Cr) & \multirow{2}{*}{ Indene oxidation reaction ${ }^{\mathrm{b}}$} & 1.42 & 71 \\
\hline 2 & HP-MIL-101(Cr) & & 1.67 & 83 \\
\hline 3 & O-MIL-101(Cr) & \multirow{2}{*}{ 1-Dodecene oxidation reaction ${ }^{\mathrm{b}}$} & 0.26 & 78 \\
\hline 4 & HP-MIL-101(Cr) & & 0.31 & 92 \\
\hline 5 & O-MIL-101(Cr) & \multirow{4}{*}{ Methanolysis of styrene oxide ${ }^{c}$} & - & $<3$ \\
\hline 6 & HP-MIL-101(Cr) & & - & $<3$ \\
\hline 7 & O-MIL-101(Cr)@PTA & & 4.54 & 17 \\
\hline 8 & HP-MIL-101(Cr)@PTA & & 7.59 & 72 \\
\hline 9 & O-MIL-101(Cr) & \multirow{5}{*}{ Dibenzoxanthene synthesis $^{\mathrm{d}}$} & 0 & 0 \\
\hline 10 & HP-MIL-101(Cr) & & 0 & 0 \\
\hline 11 & O-MIL-101(Cr)@PTA & & 13.1 & 25 \\
\hline 12 & HP-MIL-101(Cr)@PTA & & 18.9 & 90 \\
\hline 13 & PTA & & 18.4 & 92 \\
\hline 14 & O-MIL-101(Cr) & \multirow{5}{*}{$\begin{array}{l}\text { 1-(N-acetylaminophenyl- } \\
\text { methyl })-2 \text {-naphthol }{ }^{\mathrm{e}}\end{array}$} & 0 & 0 \\
\hline 15 & HP-MIL-101(Cr) & & 0 & 0 \\
\hline 16 & O-MIL-101(Cr)@PTA & & 32.8 & 26 \\
\hline 17 & HP-MIL-101(Cr)@PTA & & 45.9 & 91 \\
\hline 18 & PTA & & 45.1 & 94 \\
\hline
\end{tabular}

a) Samples were dried in the vacuum oven over night. b) Mole ratio: (indene or 1-dodecene) $/ \mathrm{H}_{2} \mathrm{O}_{2}=4: 1,70^{\circ} \mathrm{C}$, get 2-(carboxymethyl) benzoic acid and undecanoic acid, respectively. c) Molar ratio: styrene oxide/methanol=1:200, ambient temperature, get 2-phenyl-2-methoxyethanol. d) Mole ratio: benzaldehyde $/ 2$-naphthol $=1: 2,80^{\circ} \mathrm{C}$. e) Mole ratio: 2 -naphthol/benzaldehyde/acetamide $=1: 1: 1.4,130^{\circ} \mathrm{C}$. $\left.\mathrm{f}\right)$ TOF of the catalyst $=($ molar conversion of substrate)/(mass of MIL-101(Cr) $\times$ reaction time) or (moles of substrate consumed)/(mass of PTA $\times$ reaction time), depending on the reactions.

evidently facilitates the transport of the reactant and product molecules.

For a better understanding of the formation of the hierarchical structure and interfacial fusion, the following further studies were carried out.

Acetic acid acts as pre-coordinated ligand to $\mathrm{Cr}^{3+}$ for decreasing the surface crystallization and size of MIL-101 (Cr) particles because of its monocarboxylic group [28]. The similar size decrease phenomenon was also detected in experiments, with other monocarboxylic acids (Figs S12-S14). In the beginning of the reaction at room temperature, the solubility of benzene-1,4-dicarboxylic acid $\left(\mathrm{H}_{2} \mathrm{BDC}\right)$ in water is very low. The large excess of acetic acid will then pre-coordinate to $\mathrm{Cr}^{3+}$, yielding acetato-chromium complexes, including $\left[\mathrm{Cr}_{3}\left(\mu_{2}-\right.\right.$ $\left.\left.\mathrm{CH}_{3} \mathrm{COO}\right)_{6}\left(\mu_{3}-\mathrm{O}\right)\left(\mathrm{H}_{2} \mathrm{O}\right)_{3}\right]^{+}[29]$, akin to the secondary building unit (SUB) of MIL-101(Cr). With the increase in reaction temperature, the ligand $\mathrm{H}_{2} \mathrm{BDC}$ that possesses a lower $\mathrm{p} K_{\mathrm{a}}$ than acetic acid will dissolve and the deprotonated BDC anion will replace the acetate ligand at the trinuclear chromium cluster modulator, thereby linking the $\left[\mathrm{Cr}_{3}\left(\mu_{3}-\mathrm{O}\right)\left(\mathrm{H}_{2} \mathrm{O}\right)_{x}\right]$ units in the MIL framework (Fig. 3a). This procedure creates plenty of $\left[\mathrm{Cr}_{3}\left(\mu_{2}-\right.\right.$
$\left.\left.\mathrm{CH}_{3} \mathrm{COO}\right)_{6}\left(\mu_{3}-\mathrm{O}\right)\left(\mathrm{H}_{2} \mathrm{O}\right)_{3}\right]^{+}$nucleation points which accelerate the reaction rate. At the same time, and together with the finite amounts of $\mathrm{Cr}$ and BDC linker, the framework extension around each nucleation point will be limited, which leads to quite small MIL-101(Cr) particles. With the hydrothermal reaction proceeding, nanoparticles tend to agglomerate to form secondary mesopores (also large mesopores), and the interfaces of nanoparticles start to fuse together due to the low level of crystallinity of the surface, high surface energy and Ostwald ripening. This phenomenon is clearly observed in electro-microscopy (Fig. 1, Fig. 3b). Furthermore, due to the polarity difference between water and acetic acid, in a high-temperature system, well-organized macrochannels were formed by micro-phase separation (Fig. 3c) [30]. An observable macroporous structure occurs with increasing amount of acetic acid. When the ratio of $\mathrm{Cr}$ ion/acetic acid is $1: 12$, a well-organized parallel structure can be obtained.

It was interesting to check other monocarboxylic acids concerning the possible formation of HP-MIL-101(Cr). Formic acid, propionic acid, butyric acid and $n$-caprylic acid were tested as modulators. Successful synthesis of 


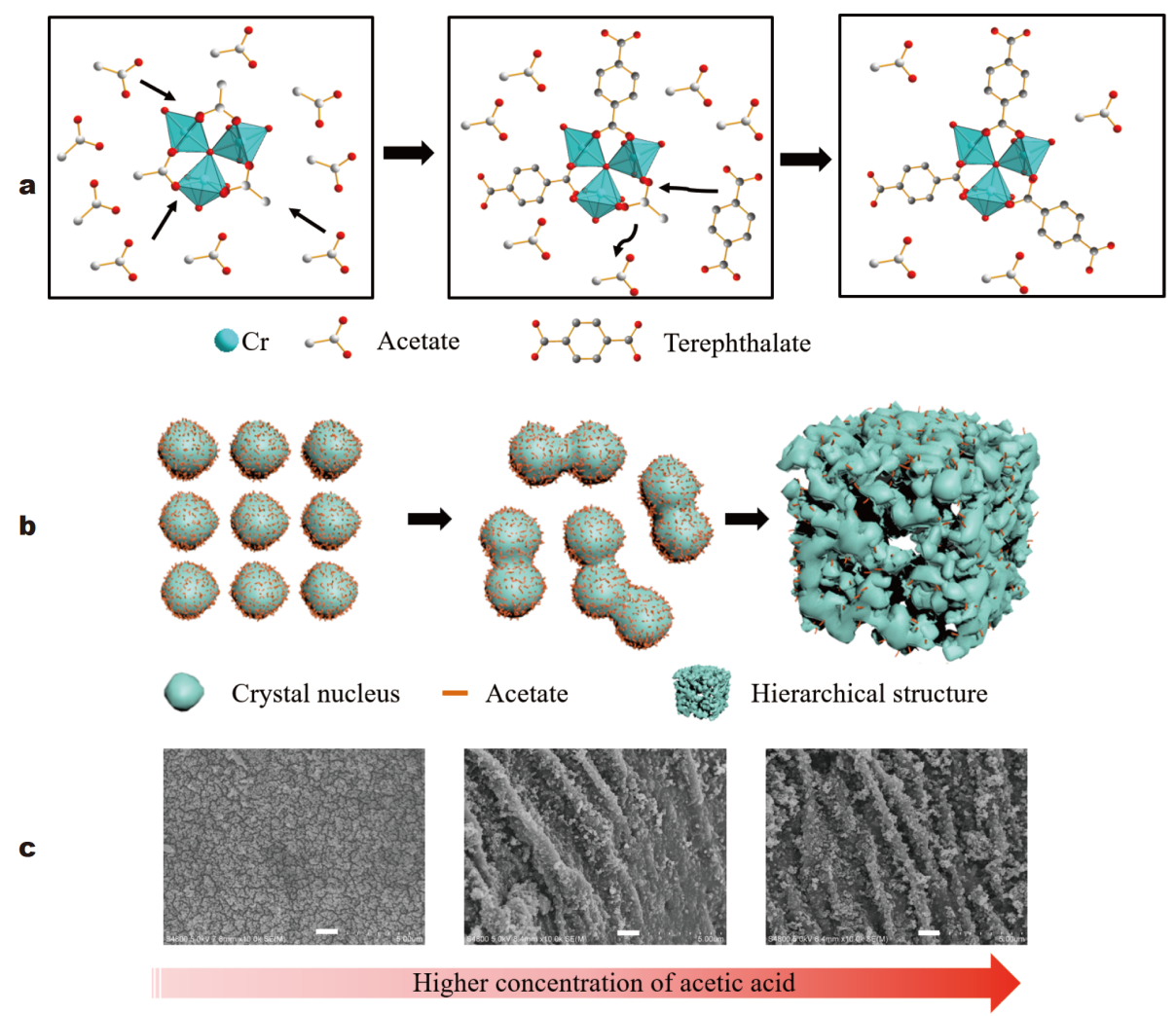

Figure 3 Schematic illustration of the formation mechanism of HP-MIL-101(Cr) with monocarboxylic acid. (a) The replacement of acetate with the terephthalate ligand. (b) The nanofusion procedure of crystal nucleus. (c) Micro-phase separation progress with high concentration at high temperature (the scale bar is $1 \mu \mathrm{m}$ ).

HP-MIL-101(Cr) was achieved for propionic acid and butyric acid (Figs S12-S14). Again, by adjusting the ratio of the $\mathrm{Cr}$ ion to other monocarboxylic acids, the macropores can be tuned (Figs S15, S16). So, the monocarboxylic acids play two roles of size decreasing and micro-phase forming. On the basis of this knowledge, it should be pointed out that formic acid does not form hierarchical MIL-101(Cr) due to the strong coordination with $\mathrm{Cr}^{3+}$. And a long-chain monocarboxylic acid, such as $n$-caprylic acid, with low solubility also failed to function as modulator to form this structure.

Unexpectedly but reproducibly, MIL-88(Cr)B material was obtained at very high doses of acetic acid, which was also found in our previous report by using benzoic acid as additive [31] (Figs S15, S16).

In summary, a template-free synthesis of hierarchical MIL-101(Cr) was achieved under hydrothermal conditions by using monocarboxylic acids as modulators at high concentrations. HP-MIL-101(Cr) has a structure of aggregated nanoparticles of $\sim 70 \mathrm{~nm}$ size, which partially coalesce or "fuse" under the used synthetic conditions. The micro-meso-macroporous material which was syn- thesized using acetic acid as a modulator features pores with 3, 20-60, and 800-1000 nm sizes. HP-MIL-101(Cr) demonstrates superior uptake of large dye molecules of Congo red compared with a control MIL-101(Cr) sample, and enhanced activity in various catalytic reactions, both in the as-synthesized form and in the form of composite with PTA.

Received 30 April 2020; accepted 22 June 2020;

published online 24 September 2020

1 Sun MH, Huang SZ, Chen LH, et al. Applications of hierarchically structured porous materials from energy storage and conversion, catalysis, photocatalysis, adsorption, separation, and sensing to biomedicine. Chem Soc Rev, 2016, 45: 3479-3563

2 Pullen S, Clever GH. Mixed-ligand metal-organic frameworks and heteroleptic coordination cages as multifunctional scaffolds: A comparison. Acc Chem Res, 2018, 51: 3052-3064

3 Feng L, Yuan S, Li JL, et al. Uncovering two principles of multivariate hierarchical metal-organic framework synthesis via retrosynthetic design. ACS Cent Sci, 2018, 4: 1719-1726

4 Jiao L, Wan G, Zhang R, et al. From metal-organic frameworks to single-atom $\mathrm{Fe}$ implanted $\mathrm{N}$-doped porous carbons: Efficient oxygen reduction in both alkaline and acidic media. Angew Chem Int Ed, 2018, 57: 8525-8529 
5 Guan HY, LeBlanc RJ, Xie SY, et al. Recent progress in the syntheses of mesoporous metal-organic framework materials. Coord Chem Rev, 2018, 369: 76-90

6 Zhu L, Zong L, Wu X, et al. Shapeable fibrous aerogels of metalorganic-frameworks templated with nanocellulose for rapid and large-capacity adsorption. ACS Nano, 2018, 12: 4462-4468

7 Wang Z, Liu T, Asif M, et al. Rimelike structure-inspired approach toward in situ-oriented self-assembly of hierarchical porous MOF films as a sweat biosensor. ACS Appl Mater Interfaces, 2018, 10: 27936-27946

8 Zhang M, Dai Q, Zheng H, et al. Novel MOF-derived Co@N-C bifunctional catalysts for highly efficient $\mathrm{Zn}$-air batteries and water splitting. Adv Mater, 2018, 30: 1705431

9 Feng D, Lei T, Lukatskaya MR, et al. Robust and conductive twodimensional metal-organic frameworks with exceptionally high volumetric and areal capacitance. Nat Energy, 2018, 3: 30-36

10 Yaghi OM, O'Keeffe M, Ockwig NW, et al. Reticular synthesis and the design of new materials. Nature, 2003, 423: 705-714

11 Deng H, Grunder S, Cordova KE, et al. Large-pore apertures in a series of metal-organic frameworks. Science, 2012, 336: 1018-1023

12 Shen K, Zhang L, Chen X, et al. Ordered macro-microporous metal-organic framework single crystals. Science, 2018, 359: 206210

13 Sun LB, Li JR, Park J, et al. Cooperative template-directed assembly of mesoporous metal-organic frameworks. J Am Chem Soc, 2012, 134: $126-129$

14 Zhang W, Liu Y, Lu G, et al. Mesoporous metal-organic frameworks with size-, shape-, and space-distribution-controlled pore structure. Adv Mater, 2015, 27: 2923-2929

15 Kim Y, Yang T, Yun G, et al. Hydrolytic transformation of microporous metal-organic frameworks to hierarchical micro- and mesoporous MOFs. Angew Chem Int Ed, 2015, 54: 13273-13278

16 Yue Y, Qiao ZA, Fulvio PF, et al. Template-free synthesis of hierarchical porous metal-organic frameworks. J Am Chem Soc, 2013, 135: 9572-9575

17 Cai G, Jiang HL. A modulator-induced defect-formation strategy to hierarchically porous metal-organic frameworks with high stability. Angew Chem Int Ed, 2017, 56: 563-567

18 Yue Y, Fulvio PF, Dai S. Hierarchical metal-organic framework hybrids: Perturbation-assisted nanofusion synthesis. Acc Chem Res, 2015, 48: 3044-3052

19 Férey G, Mellot-Draznieks C, Serre C, et al. A chromium terephthalate-based solid with unusually large pore volumes and surface area. Science, 2005, 309: 2040-2042

20 Bromberg L, Diao Y, Wu H, et al. Chromium(III) terephthalate metal organic framework (MIL-101): HF-free synthesis, structure, polyoxometalate composites, and catalytic properties. Chem Mater, 2012, 24: 1664-1675

21 Liu K, Zhang S, Hu X, et al. Understanding the adsorption of PFOA on MIL-101(Cr)-based anionic-exchange metal-organic frameworks: Comparing DFT calculations with aqueous sorption experiments. Environ Sci Technol, 2015, 49: 8657-8665

22 Wickenheisser M, Janiak C. Hierarchical embedding of micromesoporous MIL-101(Cr) in macroporous poly(2-hydroxyethyl methacrylate) high internal phase emulsions with monolithic shape for vapor adsorption applications. Microporous Mesoporous Mater, 2015, 204: 242-250

23 Wickenheisser M, Herbst A, Tannert R, et al. Hierarchical MOFxerogel monolith composites from embedding MIL-100(Fe,Cr) and MIL-101(Cr) in resorcinol-formaldehyde xerogels for water adsorption applications. Microporous Mesoporous Mater, 2015, 215: $143-153$

24 Zhao T, Jeremias F, Boldog I, et al. High-yield, fluoride-free and large-scale synthesis of MIL-101(Cr). Dalton Trans, 2015, 44: 16791-16801

$25 \mathrm{Wu}$ M, Jin J, Liu J, et al. High photocatalytic activity enhancement of titania inverse opal films by slow photon effect induced strong light absorption. J Mater Chem A, 2013, 1: 15491-15500

26 Thommes M, Kaneko K, Neimark AV, et al. Physisorption of gases, with special reference to the evaluation of surface area and pore size distribution (IUPAC Technical Report). Pure Appl Chem, 2015, 87: 1051-1069

27 Ying J, Herbst A, Xiao YX, et al. Nanocoating of hydrophobic mesoporous silica around MIL-101Cr for enhanced catalytic activity and stability. Inorg Chem, 2018, 57: 899-902

28 Zhao T, Yang L, Feng P, et al. Facile synthesis of nano-sized MIL101(Cr) with the addition of acetic acid. Inorg Chim Acta, 2018, 471: 440-445

29 Erre LS, Micera G, Glowiak T, et al. Chromium (III) acetate, chromium (III) acetate hydroxide, or $\mu 3$-oxo-esakis- $(\mu 2$-acetato-O, $\left.\mathrm{O}^{\prime}\right)$-triaqua-trichromium (III) acetate? Determining the structure of a complex compound by analytical and spectroscopic methods. J Chem Educ, 1997, 74: 432-435

30 Yang XY, Chen LH, Li Y, et al. Hierarchically porous materials: synthesis strategies and structure design. Chem Soc Rev, 2017, 46: 481-558

31 Yang L, Zhao T, Boldog I, et al. Benzoic acid as a selector-modulator in the synthesis of MIL-88B(Cr) and nano-MIL-101(Cr). Dalton Trans, 2019, 48: 989-996

Acknowledgements This work was supported by the National Key R\&D Program of China (2017YFC1103800), a joint National Natural Science Foundation of China-Deutsche Forschungsgemeinschaft (NSFC-DFG) project (NSFC 51861135313, DFG JA466/39-1), Program for Changjiang Scholars and Innovative Research Team in University (IRT_15R52), the National Natural Science Foundation of China (51802094, U1663225, U1662134, 21711530705 and 21706199), International Science \& Technology Cooperation Program of China (2015DFE52870), Hubei Provincial Natural Science Foundation of China (2016CFA033) and Hunan Provincial Natural Science Foundation of China (2018JJ3122), the S\&T Program of Hunan Province, China (2018RS3084), the Science Research Project of Hunan Provincial Department of Education (18B294) and the Fundamental Research Funds for the Central Universities (19lgzd16).

Author contributions Zhao $\mathrm{T}$ and Li S carried out all the experiments; Xiao YX, Chang G, and Tian G took part in the characterization; Janiak $\mathrm{C}$ conceived the project and revised the paper; Yang XY conceived the project, provided the idea, designed and guided the experiments, and supported scientific and technological platform. All authors contributed to the general discussion.

Conflict of interest The authors declare that they have no conflict of interest.

Supplementary information Experimental details and supporting data are available in the online version of the paper. 


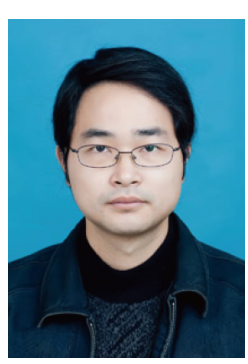

Tian Zhao completed his $\mathrm{PhD}$ under the supervision of Prof. Christoph Janiak at the University of Düsseldorf and then moved to Wuhan University of Technology as a postdoctoral research associate, working on metal-organic frameworks (MOFs) in the group of Prof. Xiao-Yu Yang. His research mainly focuses on the design, syntheses and applications of hierarchically porous materials.

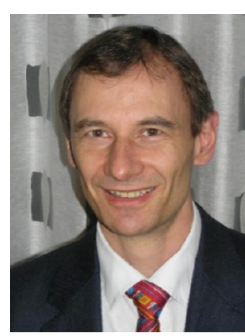

Christoph Janiak is a full professor for bioinorganic chemistry and catalysis at the University of Düsseldorf, with research interests in the synthesis and properties of metal- and porous-organic frameworks (MOFs, COFs), metal nanoparticles, ionic liquids and catalysis. Until 2018 he was a visiting professor at Wuhan University of Technology in China.

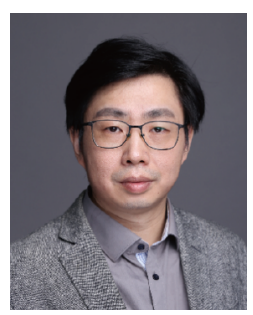

Xiao-Yu Yang received his $\mathrm{PhD}$ from Jilin University (co-educated at FUNDP of Belgium). After a postdoctoral fellowship at the FUNDP, he worked as a "Chargé de Recherches" at the FNRS in Belgium. He is currently working as full professor at Wuhan University of Technology and visiting professor at Harvard University. His research is aimed at hierarchical assembly techniques, novel porous systems, and hierarchical structured materials for the applications in energy, environment, catalysis and bioengineering.

\section{无模板法合成具有增强催化活性的分级纳米孔结} 构MIL-101(Cr)

赵田 ${ }^{1,5 \dagger}$, 李松贺 ${ }^{1 \dagger}$, 肖宇轩 ${ }^{1}$, Christoph Janiak ${ }^{4^{*}}$, 常刚刚 ${ }^{1}$, 田歌 ${ }^{1}$, 阳晓宇 ${ }^{1,2,3^{*}}$

摘要 MIL-101(Cr) 是最重要的金属有机框架 (MOFs)材料之一, 稳 定的框架结构和超高的比表面积使其在众多科学领域得到了广泛 研究和应用. 但是MIL-101 (Cr) 的合成条件比较苛刻, 且稳定性较 强, 因此, 有关于其分级结构的研究报道仍比较少. 本文提出了一 种简单制备分级纳米孔结构MIL-101(Cr) 的方法, 即以乙酸作为调 节剂, 采用水热合成的方法, 一步得到具有微孔-介孔-大孔分级结 构的MIL-101(Cr) 材料. 实验结果表明, 该分级结构的MIL-101(Cr) 与无分级结构的MIL-101(Cr)相比, 其大分子染料吸附能力和催化 能力均有显著提高. 而且分级结构MIL-101(Cr) 负载了磷铇酸催化 剂之后, 表现出了与均相催化剂(纯磷铇酸)相当的催化能力. 进一 步研究发现, 使用其他短碳链的一元羧酸作为调节剂, 如丙酸、丁 酸等, 也可获得类似分级纳米结构MIL-101(Cr). 